\title{
Cultivo de Malpighia emarginata L. no Brasil: uma revisão integrativa
}

\author{
Tainá da Silva Rorigues dos Santos ${ }^{\mathrm{a} *} \mathbb{C}^{\circ}$, Renato Abreu Lima ${ }^{\mathrm{b}}{ }^{\circledR}$ \\ a Universidade Federal do Amazonas, Brasil \\ b Universidade Federal de Rondônia, Brasil \\ *Autor correspondente (tainarodrigues_df@outlook.com)
}

\section{N F O}

\section{Keywords}

Malpighia

production

fruit

Brazil

\begin{abstract}
A B S T R A C T
Malpighia emarginata L. cultivation in Brazil: a integrative review.

The acerola, genus Malpighia, belongs to the family Malpighiaceae, this botanical family has a pantropical distribution, including 75 genera and about 1,300 species. Thus, this study aimed to carry out an integrative bibliographic review in specialized databases on the cultivation of acerola in Brazil. It was found that recently, in Brazil, there has been a considerable expansion of the area cultivated with acerola, genus Malpighia, this event is due to its nutritional qualities, having proteins, calcium, phosphorus, iron and vitamins A, B1, B2, and C, being the flagship with up to 100 times more than in other citrus fruits such as orange, lemon, etc., cultivation facilities and for having an excellent edaphoclimatic adaptation, such expansion is proven by the short time that the plant was spread in the country, since 1955, as it is a plant native to the Caribbean Islands, Central America and North South America. Its cultivation was intensified in the period from 1988 to 1992, due to its importance for human food, and today the Brazil is considered the largest producer of the fruit, with Malpighia emarginata DC and Malpighia glabra L. being the most commercially cultivated species. Generating productive, financial, and social benefits. The good acceptance of the fruit, both in natura fruit and its derivatives, by the national and international market is an important incentive for large-scale production.
\end{abstract}

\section{R E S U M O}

A acerola, gênero Malpighia, pertence à família Malpighiaceae, esta família botânica possui distribuição pantropical, incluindo 75 gêneros e cerca de 1.300 espécies. Assim, o presente trabalho teve como objetivo realizar uma revisão bibliográfica integrativa em bancos de dados especializados sobre o cultivo da acerola no Brasil. Verificou-se que recentemente, têm-se constatado no Brasil, considerável expansão da área cultivada com acerola, gênero Malpighia, esse acontecimento se dá por suas qualidades nutricionais, possuindo proteínas, cálcio, fósforo, ferro e vitaminas A, B1, B2,e C, sendo está o carro chefe com até 100 vezes mais do que em outras frutas cítricas como laranja, limão, etc., facilidades de cultivo e por ter ótima adaptação edafoclimática, tal expansão é comprovada pelo pouco tempo em que a planta foi difundida no país, desde 1955, pois é uma planta nativa das Ilhas do Caribe, América Central e Norte da América do Sul. Seu cultivo foi intensificado no período de 1988 a 1992, em virtude da sua importância para a alimentação humana, e nos dias atuais o Brasil é considerado o maior produtor do fruto, sendo a Malpighia emarginata D. C. e Malpighia glabra L. as espécies mais cultivadas comercialmente. Gerando benefícios produtivos, financeiros e sociais. A boa aceitação do fruto, tanto do fruto in natura quanto seus derivados, por parte do mercado nacional e internacional é um incentivo de grande importância para a produção em grande escala. 


\section{INTRODUÇÃO}

A acerola, gênero Malpighia, compete à família Malpighiaceae, esta família botânica possui distribuição pantropical, incluindo 75 gêneros e cerca de 1.300 espécies (Alves e Sebastiani, 2015). O centro de diversidade do grupo concentra-se na América do Sul em áreas de Cerrado, no Brasil há 44 gêneros e 561 espécies (Mamede et al., 2015).

No Brasil, seu cultivo foi intensificado no período de 1988 a 1992, em virtude da sua importância para a alimentação humana, em função da riqueza em vitamina C, estimada entre 1200 a $1900 \mathrm{mg} \mathrm{100}^{-}$ ${ }^{1} \mathrm{~g}$ de polpa (Paiva et al., 2003). Recentemente, têm-se constatado no Brasil, considerável expansão da área cultivada com acerola, principalmente, por suas qualidades nutricionais, facilidades de cultivo e ótima adaptação edafoclimática. Esses fatores, sem dúvida, foram responsáveis pelo surgimento de pomares comerciais e, paralelamente, a necessidade de adoção de tratos culturais, nutrição e adubação, entre outras técnicas, no combate a pragas e doenças (Alves et al., 2009). Assim, o presente trabalho teve como objetivo realizar uma revisão bibliográfica integrativa sobre o cultivo da acerola no Brasil.

\section{MATERIAL E MÉTODOS}

O presente trabalho se trata de um artigo de revisão literária e tem como objetivo descrever as principais fases do cultivo de acerola, gênero $\mathrm{Mal}$ pighia, com embasamento em artigos que foram publicados no período de 1996 a 2019. O critério de inclusão foram trabalhos publicados nos últimos 23 anos e os critérios de exclusão foram trabalhos publicados em inglês. Os bancos de dados aos quais a pesquisa foi realizada incluíam: Embrapa; Scielo e Google Acadêmico. Além disso, os descritores utilizados para busca de trabalhos foram: acerola, importância de acerola, Malpighia emarginata D.C., Malpighia glabra L., acerola no Brasil, gênero Malpighia, cultivo de acerola, colheita de acerola, Malpighiaceae, importância econômica de acerola no Brasil, tratos culturais de acerola, aceroleira, colheita de acerola, curiosidades sobre acerola, plantar acerola, espécies do gênero Malpighia.

\section{RESULTADOS E DISCUSSÃO}

A acerola possui a seguinte classificação científica: Reino: Plantae; Ordem: Malpighiales; Família: Malpighiaceae; Gênero: Malpighia; e as espécies mais representativas são: Malpighia emarginata D.C., Malpighia glabra L., Malpighia berteroana, Malpighia uren, Malpighia biflora, Malpighia dicipiens, Malpighia fallax, Malpighia lucida, Malpighia myrtoides, Malpighia neumanniana, Malpighia nitida, Malpighia oxycocca, Malpighia peruviana, Malpighia punicifolia, Malpighia semeruco, Malpighia undulata, Malpighia uniflora, Malpighia virgata, Malpighia retusa, Malpighia umbellata (Patro, 2014), Malpighia aquifolia, Malpighia coccigera, Malpighia cubensis, Malpighia ilicifolia, Malpighia mexicana, Malpighia suberosa (Malpighia, 2016).

\section{Origem no Brasil}

De acordo com Ritzinger e Ritzinger (2011), a aceroleira é uma frutífera nativa das Ilhas do Caribe, América Central e Norte da América do Sul. O Brasil é um dos poucos países que cultivam comercialmente a acerola, que foi, inicialmente, introduzida no estado de Pernambuco, pela Universidade Federal Rural de Pernambuco (UFRPE) em 1955, por meio de sementes oriundas de Porto Rico, de onde se espalhou para o Nordeste e para outras regiões do país. Atualmente, é cultivada em todos os estados brasileiros, com limitações na região Sul por suas temperaturas extremamente baixas no inverno.

É cultivada comercialmente, no Brasil, desde meados dos anos 80, principalmente no Nordeste, com destaque para os estados de Pernambuco, $\mathrm{Pa}$ raíba, Bahia e Ceará (Codevasf, 2019). Outros Estados, como Pará, São Paulo e Minas Gerais, situados nas Regiões Norte e Sudeste, também vem se destacando na produção de acerola. De acordo com IBGE (2017) o ranking em toneladas produzidas pelos dez maiores estados produtores foram: $1^{\circ} \mathrm{Per}-$ nambuco 21.351 ton.; $2^{\circ}$ Ceará 7.578 ton.; $3^{\circ}$ Sergipe 5.427 ton.; $4^{\circ}$ Paraíba 4.925 ton.; $5^{\circ}$ Piauí 4.690 ton.; $6^{\circ}$ São Paulo 3.907 ton.; $7^{\circ}$ Pará 3.695 ton.; $8^{\circ}$ Paraná 3.286 ton.; $9^{\circ}$ Bahia 2.023 ton. e $10^{\circ}$ Espírito Santo com 915 ton.

Como os países desenvolvido do Hemisfério Norte estão cada vez mais ávidos por produtos naturais, sobretudo frutas procedentes dos trópicos, o cultivo de acerola para fins de exportação destacase como uma alternativa agrícola real (Mendes et al., 2012). De acordo com Ritzinger e Ritzinger (2011), as espécies mais cultivadas comercialmente no Brasil são Malpighia emarginata D.C. e Malpighia glabra L.

\section{Morfologia}

Ritzinger e Ritzinger (2011) cita que a aceroleira é uma planta arbustiva de hábito de crescimento 
que varia de prostrado a ereto, com copa aberta ou compacta, que pode chegar a 2,5 a 3,0 m de altura, quando adulta. A casca do caule e dos ramos é levemente rugosa, de cor marrom em ramos jovens e acinzentada no caule e ramos mais velhos. As folhas são opostas com pecíolo curto, ovaladas ou elíptico-lanceoladas, medindo de 2 , a 7,5 cm, de coloração verde-escuro e brilhante na face superior e verde pálido na inferior. Possui inflorescência com 2 a 4 flores em média hermafroditas, de coloração rósea a violeta esbranquiçada (Barboza et al., 1996). Ainda, apresenta dez estames, três estiletes, três carpelos unidos, formando um ovário globular, súpero, triloculado, cada lóculo contendo um óvulo. É característica do cálice a presença de duas glândulas grandes em cada sépala, localizadas na parte basal externa (Joly, 1983).

Os grãos de pólen da aceroleira são amarelos, pegajosos, não dissemináveis pelo vento, sendo a polinização dependente de insetos polinizadores nativos como abelhas do gênero Centris spp. A viabilidade do pólen pode variar de 10 a $90 \%$, a depender do genótipo (Ritzinger e Ritzinger, 2011).

Os frutos da aceroleira são drupas de forma arredondada, ovalada ou cônica e quando maduros de cor vermelha, roxa ou amarela (Cavalcante, 2015). A superfície do fruto pode ser lisa ou apresentar, entre os carpelos, sulcos rasos ou profundos. Crescem isoladas ou em cachos de dois ou mais frutos, sempre na axila das folhas. Os frutos são pequenos, com peso médio de 3 a $16 \mathrm{~g}$, variando em virtude do potencial genético da planta e das condições de cultivo. Em geral, os frutos que crescem isolados são maiores que os que formam cachos (Mendes et al., 2012).

As sementes são pequenas, monoembriônicas, não albuminadas, apresentando, na extremidade mais estreita, uma pequena saliência, que é a radícula embrionária. A acerola apresenta baixa produção de sementes viáveis, sendo que, em geral, a quantidade de caroços com sementes varia de $20 \%$ a 50\% (Ritzinger e Ritzinger, 2011).

O fruto da aceroleira possui vitaminas A, B1, B2, $\mathrm{C}$ (até 100 vezes mais do que em outras frutas cítricas como laranja, limão, etc.), proteínas, cálcio, fósforo e ferro. $\mathrm{O}$ valor calórico está em torno de $60 \mathrm{kcal}$ em 100 gramas de polpa (Azevedo, 2019).

\section{Clima}

Por ser uma planta rústica, a aceroleira desenvolve-se bem tanto em clima tropical quanto subtropical, com uma temperatura ideal em torno de 26 ${ }^{\circ} \mathrm{C}$ (Alves et al., 2009). Com relação à altitude desenvolve-se bem desde o nível do mar até $800 \mathrm{~m}$ de altitude (Barboza et al., 1996).

Embora adaptada para cultivo em regiões semiáridas, a sua maior produção ocorre em regiões com precipitação entre 1200 e $1600 \mathrm{~mm}$ anuais, bem distribuídos (Gonzaga Neto e Soares, 1994).

A qualidade dos frutos da aceroleira é grandemente influenciada pela radiação solar, existindo uma correlação positiva entre o teor de ácido ascórbico e a intensidade da radiação solar (Alves et al., 2009). Gomes et al. (2002) afirmam que aceroleiras que recebem maior radiação solar (em horas-luz) tem maiores quantidades de ácido ascórbico, em relação a aceroleiras que recebem menos radiação solar.

\section{Solo}

A aceroleira não é muito exigente quanto ao tipo de solo, podendo ser cultivada em solos arenosos e em solos argilosos, desde que se adotem os devidos cuidados de adubação e drenagem, dependendo do tipo de solo utilizado (Alves et al., 2009). Entretanto, os solos mais adequados ao seu cultivo são os de fertilidade mediana e os argiloarenosos. A faixa de $\mathrm{pH}$ considerada como ótima para aceroleira está entre 5,5 e 6,5, com saturação por bases em torno de 70\% (Mendes et al., 2012).

\section{Plantio}

A propagação da aceroleira pode ser sexuada (por sementes) ou por via vegetativa (estaquia ou enxertia). A germinação das sementes pode ser feita em canteiros ou diretamente nos recipientes de formação das mudas (sacos ou tubetes). Quando a propagação for feita por estaquia, recomenda-se a utilização de estacas cerca de $30 \mathrm{~cm}$, provenientes de ramos vigorosos oriundos de plantas jovens. As estacas devem ser tratadas com ácido indolbutírico (IBA) e colocadas para enraizar em substrato de areia ou vermiculita. A propagação por enxertia favorece a formação de um sistema radicular mais vigoroso (Alves et al., 2009).

Os espaçamentos mais indicados para o seu cultivo variam de $4 \times 4 \mathrm{~m}$ (625 plantas/ha) 4 × $3 \mathrm{~m}$ (833 plantas/ha) e 5 x 4 m (500 plantas/ha). As covas de plantio devem ter as dimensões de $0,40 \mathrm{x}$ $0,40 \times 0,40 \mathrm{~m}$. (Filho et al., 2019). O plantio pode ser realizado durante o ano todo, mas deve-se dar preferência ao início da estação chuvosa. As mudas devem ter $30 \mathrm{~cm}$ de altura, (Franzão e Melo, 2019). Todas as calagens e adubações deverão ser feitas de acordo com as análises de solo e necessidades da planta.

\section{Tratos culturais}

A irrigação é uma prática necessária, uma vez que o cultivo econômico da cultura se adapta bem 
a locais onde as precipitações são escassas e distribuídas de maneira irregular, como é o caso do Nordeste brasileiro. Pode ser usada para regular os ciclos florais, já que, sob condições de irrigação, a aceroleira pode florir durante todo ano. (Mendes et al., 2012) adapta-se bem aos seguintes métodos de irrigação: aspersão convencional, microaspersão, gotejamento, gotejamento subsuperficial, mangueiras perfuradas a laser e sulcos (Alves et al., 2009). A escolha do método de irrigação depende dos recursos hídricos do local, topografia do terreno, clima, solo e disponibilidade de recursos financeiros do produtor (Cavalcante, 2015).

Após o plantio é essencial o tutoramento para auxiliar na condução do crescimento inicial das plantas. Até a muda atingir 30 a $40 \mathrm{~cm}$ de altura, serão necessárias podas de formação para conduzi-la em haste única. A partir daí, devem-se deixar de três a quatro ramos até a planta atingir 50 a $60 \mathrm{~cm}$ de altura, momento em que é feito um desponte, para quebrar a dominância apical. Os ramos ladrões devem ser eliminados e, sistematicamente, após cada ciclo de produção, realizar poda mantendo as plantas na altura adequada (Alves et al., 2009). O coroamento deve ser feito em um raio de $1 \mathrm{~m}$ ao redor da muda recém-plantada, e quando a aceroleira já está formada, deve-se fazer a capina até $1 \mathrm{~m}$ além da projeção da copa (Mendes et al., 2012).

Os grãos de pólen da aceroleira são amarelos, pegajosos, não dissemináveis pelo vento, sendo a polinização dependente de insetos polinizadores nativos como abelhas do gênero Centris spp (Ritzinger e Ritzinger, 2011).

Nos plantios de acerola, o controle de plantas daninhas tem o objetivo principal de evitar que estas prejudiquem o desenvolvimento da aceroleira e pode ser feito de forma manual, químico ou mecânico (Ritzinger e Ritzinger, 2011). Nos primeiros anos de vida do pomar, no espaço entre linhas de plantas podem-se plantar culturas intercalares de pequeno porte como feijão, amendoim, batata-doce e mandioca ou fruteiras. Mantendo-se um metro de distância das plantas de acerola e receber adubação específica, para não prejudicar a cultura principal (Barboza et al., 1996).

Em áreas com sistema artificial de irrigação, recomenda-se a utilização de herbicidas, para reduzir os danos causados ao sistema de irrigação em função do corte nas mangueiras. Recomenda-se, ainda, a utilização de cobertura morta na projeção da copa, a qual proporciona não somente o controle de plantas invasoras, como ajuda na conservação da umidade do solo (Alves et al., 2009).

As pragas [(bicudo-do-botão-floral (Anthony acerolae); cigarrinha (Bolbonata tuberculata), percevejo-vermelho (Crinocem sanctus); cochonilhaparda (Coccus hespiridium); formigas-cortadeiras
(Atta spp.); mosca-das-frutas (Ceratitis capitata); ortézia (Orthezia praelonga); e pulgão (Aphis spp.)] e os fungos [Antracnose (Collerotrichum gloeosporioides); Antracnose (Collerorrichum demarlum); Mancha das folhas (Cercospora bunchsuae); Mancha-cinza (Myrorhecium roridum); Verrugose (Sphaceloma sp); Podridão dos frutos( Rhizopus sp); Seca dos ramos e cancros do caule (Lesiodiplodia theobromse); Podridão das raízes (Fussrium solani);Mancha de alga (Cephaleuros rescens); Nematoides das galhas (Meloidogyne incognifa); Nematóides das galhas (Meloidogyne javenics); Nematóides das galhas (Meloidoqyne arcuaria)] devem ser eliminados com pesticidas, fungicidas e práticas adequada a cada espécie. $\mathrm{E}$ as doenças devem ser sanadas de acordo as necessidades da planta.

\section{Colheita}

A operação de colheita é sem dúvida uma das mais delicadas e de maior custo no cultivo de acerola (Barboza et al., 1996). É feita manualmente e a coloração externa do fruto é o principal critério para estimar o grau de maturação. À medida que o fruto vai atingindo a coloração vermelho intensa, seu teor de vitamina $\mathrm{C}$ diminui (Mendes et al., 2012). De acordo com Ritzinger e Ritzinger (2011), é recomendável que os colhedores usem roupas adequadas, visto que a pilosidade presente nas brotações novas pode causar irritações na pele.

O fator determinante do ponto de colheita é o destino que se pretende dar aos frutos, (Ferreira et al., 2009). Para venda como fruta fresca em mercados locais e para congelamento ou processamento na forma de suco ou polpa, os frutos devem ser colhidos com coloração vermelho-intensa (maduros), mas ainda firmes para suportar o manuseio (Ritzinger e Ritzinger, 2011). Para a extração de vitamina $\mathrm{C}$, o ponto de colheita ideal é verde, pois ocorre redução dessa vitamina com a maturação dos frutos (Ferreira et al., 2009).

\section{Pós-colheita}

A partir da realização da colheita, os frutos devem ser mantidos à sombra, pois sua exposição à radiação solar diminui o teor de vitamina C e os deprecia por perda de umidade (Ritzinger e Ritzinger, 2011). Pelo fato de serem bastante perecíveis, recomenda-se que os frutos sejam levados ao seu destino logo após a colheita. Caso a distância seja longa, devem ser congelados, embalados em caixas de isopor e transportados em câmaras frigoríficas (Mendes et al., 2012).

Ainda de acordo com Ritzinger e Ritzinger (2011), algumas etapas importantes do pós-colheita 
são: a seleção rigorosa para eliminar os feridos, podres, moles, imaturos e detritos. Em seguida, os frutos são lavados, com água fria e clorada. Os frutos destinados ao consumo in natura são acondicionados em embalagens plásticas, pesados e conservados por refrigeração à temperatura de $7 \mathrm{a} 8{ }^{\circ} \mathrm{C}$ tendo conservação por um período de até 10 dias a partir da colheita, viável apenas para mercados mais próximos.

Assim, o amadurecimento e a senescência de frutos podem ser vistos como fenômenos oxidativos e a seleção de variedades com maior capacidade enzimática antioxidante é uma alternativa para obtenção de frutos que podem ser armazenados por períodos mais longos sem perder seus atributos de qualidade (Cunha-Neto et al., 2012).

\section{Importância econômica e social}

O cultivo de acerola vem acentuando de forma persistente e tem despertado interesse entre os produtores e consumidores brasileiros ou estrangeiros, tanto in natura ou outros subprodutos industriais (Franzão e Melo, 2019). São poucos os países que cultivam comercialmente a acerola e o Brasil se sobressaem nesse contexto, sendo atualmente o maior produtor, exportador e consumidor (Silveira et al., 2020).

O cultivo em grande escala, para comercialização, gera muitos empregos, desde a produção e comercialização do fruto e seus derivados, tais como: mão-de-obra para produção de mudas, plantio, tratos culturais, colheita, pós-colheita, comercialização direta (produtor-comerciante), comercialização indireta (comerciante-consumidor) e fretes. As etapas caracterizadas como de mão-de-obra mais intensiva são as etapas de colheita e classificação dos frutos (Franzão e Melo, 2019). Com a geração de empregos aumenta a circulação financeira da região de produção, pois há compra de insumos e contratação de mão de obra, assim como da região de comercialização e consumo. Fatos que tornam o cultivo de acerola importante economicamente e socialmente. Seu aproveitamento é possível em produtos, como compotas, geleias, sucos e suplementos alimentares, entre outros (Caetano et al., 2012).

\section{CONCLUSÕES}

Com base nas informações do presente artigo de revisão bibliográfica integrativa, pode-se afirmar que a produção de acerola vem aumentando de maneira positiva no Brasil, desde sua disseminação pelo país, por consequência de seus valores nutricionais e aptidão da fruteira as condições edafoclimáticas do Brasil. A boa aceitação do fruto, tanto do fruto in natura quanto seus derivados como geleias, sucos, doces, cosméticos, medicamentos, por parte do mercado nacional e internacional é um incentivo de grande importância para a produção em grande escala.

A produção de acerola, além de seus valores nutricionais para alimentação e fármacos, também, se destaca pelo valor social e financeiro, pois gera empregos e faz movimentações financeiras diretas e indiretas na região de produção e nas regiões de exportação. Tais características tão positivas faz-se pensar que o cultivo de acerola só tende a continuar aumentando nas próximas décadas, pois a exportação e importação de acerola ganha cada vez mais espaço no mercado.

\section{REFERÊNCIAS BIBLIOGRÁFICAS}

Acerola (Malpighia emarginata DC.). 30 jul. 2016. Disponível em: http://organicamentefeliz.blogspot.com/2016/07/acerola.html. Acesso em: 26 maio 2019.

Alves GGN, Sebastiani R. Malpighiaceae na Reserva Biológica do Alto da Serra de Paranapiacaba, Santo André, SP, Brasil, São Paulo, 2015. Disponível em: http://www.scielo.br/scielo.php?script=sci_arttext\&pid=S223689062015000300521 . Acesso em: 23 de maio 2019.

Alves RE et al. Adubando para alta produtividade e qualidade fruteiras tropicais do Brasil. Fortaleza-CE: A.E. Johnston, 2009.

Azevedo RB, Acerola. [S. l.], 2019. Disponível em: https://www.portalsaofrancisco.com.br/alimentos/acerola. Acesso em: 23 de maio 2019.

Barboza, SB; Tavares, ED; Melo, MB. instruções para o cultivo da acerola. Aracaju SE: Gráfica e Editora Triunfo Ltda., 1996.

Caetano PK, Daiuto ÉR, Vieites RL. Característica físico-química e sensorial de geleia elaborada com polpa e suco de acerola. Brazilian Journal of Food Technology, v.15, n.3, p.191-197, 2012.

Cavalcante ÍHL. Cultura da aceroleira. 2015. Disponível em: http://www.frutvasf.univasf.edu.br/images/aulaaceroleira.pdf. Acesso em: 23 de maio 2019.

Codevasf. Censo frutícola 2001. Brasília, 2001. Disponível em: <http://www.codevasf.gov.br/fruticultura/>. Acesso em: 18 de maio 2019

Cunha-Neto J, Rabelo MC, Bertini CHCM, Marques GV, Miranda MRA. Caracterização agronômica e potencial antioxidante de frutos declones de aceroleira. Revista Ciência Agronômica, v.43, n.4, p.713-721, 2012.

Ferreira, RMA et al. Ponto de colheita da acerola visando à produção industrial de polpa. Mossoró - RN, 2009. Disponível em: https://www.researchgate.net/publication/264992563_ponto_de_colheita_da_acerola_visando_a_producao_industrial_de_polpa_punto_de_cosecha_de_la_acerola_visando_a_la_produccion_industrial_de_pulpa. Acesso em: 11 de maio 2019.

Franzão AA, Melo BA. Cultura da Aceroleira. [S. l.], 2019 Disponível em: http://www.fruticultura.iciag.ufu.br/aceroleira.htm. Acesso em: 11 maio 2019. 
Filho GAF, Leite JBV, Ramos JV. Acerola. [S. l.], 2019. Disponível em: http://www.ceplac.gov.br/radar/acerola.htm. Acesso em: 11 maio 2019.

Gomes JE, Perecin D, Martins ABG. Correlações entre os caracteres físico-químicos de frutos da aceroleira com variáveis meteorológicas. Revista brasileira de fruticultura, $[s$. L.], v. 24, ed. 1, 2002. Doi https://doi.org/10.1590/s010029452002000100024. Disponível em: https://www.scielo.br/scielo.php?script=sci_arttext\&pid=s010029452002000100024. Acesso em: 24 set. 2020.

IBGE. Ranking - Acerola dos Estados do Brasil por Quantidade produzida. IBGE, [S. l.], 30 set. 2017. Disponível em: https://censos.ibge.gov.br/agro/2017/templates/censo_agro/resultadosagro/agricultura.html?localidade $=0 \&$ tema $=76215$. Acesso em: 25 set. 2020 .

Instituto Agronômico De Campinas. Acerola. São Paulo-SP, 2019. Disponível em: http://www.iac.sp.gov.br/areasdepesquisa/frutas/frutiferas_cont.php?nome=Acerola. Acesso em: 23 de maio 2019.

Joly AB. Botânica: introdução à taxonomia vegetal. 6.ed. São Paulo: Nacional, 1983. 778p.

Malpighia coccigera. [S. l.], 27 abr. 2016. Disponível em: https://mybonsai.com.br/articles/view/93. Acesso em: 25 maio 2019.

Mamede, MCH., Sebastiani, R., Almeida, RF., Francener, A, Amorim, AMA. 2015. Malpighiaceae. In: Lista de Espécies da Flora do Brasil. Jardim Botânico do Rio de Janeiro. Disponível em http://floradobrasil.jbrj.gov.br/jabot/floradobrasil/FB155 (acesso em: 25 set. 2020).

Mendes AMS. et al. A Cultura Da Acerola. Brasília, DF: Embrapa, 2012.

Paiva JR et al. Clones de aceroleira: BRS 235 ou Apodi, BRS 236 ou Cereja, BRS 237 ou Roxinha e BRS 238 ou Frutacor1. Fortaleza - CE, 2003. Disponível em: https://www.embrapa.br/busca-de-publicacoes/-/publicacao/425142/clonesde-aceroleira-brs-235-ou-apodi-brs-236-ou-cereja-brs-237ou-roxinha-e-brs-238-ou-frutacor. Acesso em: 11 de maio 2019.

Patro R. Acerola - Malpighia emarginata. [S. l.], 23 set. 2014. Disponível em: https://www.jardineiro.net/plantas/acerolamalpighia-emarginata.html. Acesso em: 25 de maio 2019.

Ritzinger R, Ritzinger CHSP. Acerola. Informe Agropecuário, Belo Horizonte, 2011.

Teixeira S. Produção de acerola - principais variedades comerciais. 2019. Disponível em: https://www.cpt.com.br/artigos/producao-de-acerola-principais- variedades-comerciais. Acesso em: 26 maio 2019.

Silveira GCD, Rossi MFM, Peche PM. Acerola: Detalhes do cultivo no Brasil. Campo \& Negócio Online, [s. L.], 24 jun. 2020. Disponível em: https://revistacampoenegocios.com.br/acerola-detalhes-do-cultivo-no-brasil/. Acesso em: 25 set. 2020. 